\title{
Research on the Relationship Between Industrial Cluster and Technological Innovation Diffusion-An Empirical Research of Chinese Construction Industry
}

\author{
Xiaochen Chen \\ School of Economics and Management \\ Beijing Jiaotong University \\ Beijing, China \\ 17120726@bjtu.edu.cn
}

\begin{abstract}
This paper uses Granger causality test to analyze the relationship between the degree of agglomeration of Chinese construction industry and the diffusion of technological innovation. Research shows that in Beijing, Anhui and Jiangxi, the construction industry clusters can obviously promote the technological progress of the industry, and technological progress on the promotion of the cluster effect is not significant. Therefore, the construction industry cluster should be developed to create a good environment for the technological innovation.
\end{abstract}

Keywords-Industrial clusters; Diffusion of technological innovation; Chinese construction industry introduction

\section{INTRODUCTION}

At present, China's economy has entered the 'new normal' stage, economic growth is facing an important historical moment of transformation from the essential factor-driven growth model to the technology innovation-driven growth model. Technology innovation is the first successful application of new technology [1], and technology diffusion is the cumulative effect of technology innovation, it can maximize the potential economic benefits of technology innovation [2].

Industrial clusters refer to the functional groups which are assembled in a certain geographical area by several similar enterprises which produce a certain product, as well as the upstream and downstream enterprises, the related service industry, and the regulation and management organizations that are supporting these enterprises. The success of technological innovation in industrial clusters depends not only on the depth and advancement of technological innovation, but also on the degree of diffusion of technological innovation. In recent years, the construction industry of China develops rapidly with the growth of the national economy, but as the pillar industry of the national economy of China, the proportion of the added value of the construction industry to the gross domestic product (GDP) has been lower than the normal level of the international industry, the labor productivity only accounts for $30 \%-40 \%$ of the developed countries such as Europe, America and Japan, and the profit rate of the construction enterprises' output value hovers in $2.6 \%-3.1 \%$ [2] in recent 5 years. In addition, the contradiction between China's construction industry and resource consumption, environmental protection is also increasingly prominent. Faced with the above difficulties in China's construction industry, promoting technological innovation and diffusion of technological innovation has become an important way to solve the problem. problems.

Many scholars have made contributions to the study of industrial clusters and technological innovation. Saxenian (1990) pointed out that the formation of dynamic networks in clusters is conducive to the emergence of high-tech enterprises in clusters [3]. Belussi and Arcangeli (1998) found that the learning between enterprises can promote the technological innovation and diffusion of cluster enterprises [4]. Sun and $\mathrm{Ma}$ (2012) found that the insufficiency of the vitality of traditional industrial clusters' technological innovation, but the speed of technological innovation diffusion is fast, while the vitality of high-tech industrial clusters is sufficient but the speed of diffusion is slow [5]. On the basis of these studies, this paper takes the Chinese construction industry as the research object, explores the relationship between the construction industry cluster and the diffusion of construction technology innovation, and tries to provide some research references for the development of Chinese construction industry.

\section{RESEARCH METHODOLOGY}

\section{A. Index Selection}

1) Industrial Cluster Level Index: This paper chooses the location entropy coefficient to measure the regional agglomeration degree of Chinese construction industry.

$$
L Q_{i j}=\frac{E_{i j} / E_{i}}{E_{k j} / E_{k}}
$$

In the (1), $E_{i j}$ is the employment/industrial output value of industry $\mathrm{j}$ in the region $\mathrm{i}, \mathrm{E}_{\mathrm{i}}$ is the total employment/industrial output value of the region $i, E_{k j}$ is the total employment/industrial output value of industry $\mathrm{j}$ in the whole country or province $\mathrm{k}, \mathrm{E}_{\mathrm{k}}$ is the total employment/industrial output value of national or province $\mathrm{k}$.

This paper calculates the location entropy coefficients of construction industry in 31 regions in China from 2000 to 2016 and all the data are from the China Statistical Yearbook (20012017). Finally, eleven regions with high degree of clusters and relatively stable level of clusters are selected as the research objects: Beijing, Jiangsu, Zhejiang, Fujian, Yunnan, Hunan, Hubei, Chongqing, Sichuan, Anhui and Jiangxi. 
2) Index of diffusion level of technological innovation: Initially, this paper chooses labor productivity and technical equipment ratio as the measure index of the diffusion level of technological innovation in Chinese construction industry. But in the last 10 years, the change range of technical equipment rate is very small, but the change range of labor productivity is very big, the speed of growth is relatively fast, which shows that the technical innovation of the construction industry in the last ten years has a very small promotion effect on the technical equipment rate, and the promotion effect on the labor productivity is obvious. Therefore, this paper will ultimately select the labor productivity as an indicator to measure the diffusion level of technological innovation in the construction industry in ten regions such as Beijing.

\section{B. Stationarity Test}

In this paper, the Granger causality test model is used to conduct empirical research. But when both variables are nonstationary time series, the Granger causality test for the two variables may be false, so we use Augmented Dickey-Fuller test (ADF) to test the stationarity of the variables. After texting, the time series of Beijing are integrated of order 1, and the time series of Hubei, Anhui, and Jiangxi are integrated of order 2. Data from other seven regions are not uniformity integrated variables.

\section{Covariance Analysis}

For uniformity integrated variables, the next step is to conduct covariance analysis. In this paper, we use EngleGranger (EG) method to test covariance of variables. Through analysis, the time series of Beijing, Jiangxi and Anhui have a long and stable co-integration relationship, so they can be tested by the following Granger causality test.

\section{Grainger Causality Test Model}

After the data pass the stationarity test and the covariance analysis, the Granger causality test can be carried out.

$$
Y_{t}=\sum_{i=1}^{m} \alpha_{i} X_{t-i}+\sum_{i=1}^{m} \beta_{i} Y_{t-i}+\mu_{1 t}
$$

$$
X_{t}=\sum_{i=1}^{m} \lambda_{i} Y_{t-i}+\sum_{i=1}^{m} \delta_{i} X_{t-i}+\mu_{2 t}
$$

In the (2) and (3), $X_{t}, Y_{t}$ are the current values of $X, Y$ primitive sequences. $\mathrm{X}_{\mathrm{t}-\mathrm{i}}$ and $\mathrm{Y}_{\mathrm{t}-\mathrm{i}}$ are the values of $\mathrm{X}$ and $\mathrm{Y}^{\prime} \mathrm{s}$ original sequence lag i period. $\alpha_{i}, \beta_{i}, \lambda_{i}$ and $\delta_{i}$ are regression coefficients. The error terms are $\mu_{1 \mathrm{t}}$ and $\mu_{2 \mathrm{t}}$. The Granger test is done by using the F-test. For example, according to the assumption that $\mathrm{X}$ is not the Granger cause of $\mathrm{Y}$, the regression including the $\mathrm{X}$-lag term and the regression excluding the $\mathrm{X}$ lag term are done respectively. The sum of the residual squares of the first regression is $\mathrm{RSS}_{\mathrm{U}}$, the sum of the residual squares of the second regression is $\mathrm{RSS}_{\mathrm{R}}$, and then the F-statistics are calculated:

$$
F=\left(R S S_{R}-R S S_{U}\right) \times(N-2 n-1) / R S S_{U} \times n
$$

In the (4), $\mathrm{n}$ is the number of hysteresis terms of $\mathrm{X}$ and $\mathrm{N}$ is the sample size. If the calculated $F$ value is greater than the critical value $\mathrm{F} \alpha(\mathrm{n}, \mathrm{N}-2 \mathrm{n}-1)$ of the $\mathrm{F}$ distribution at a given significant level, then the original hypothesis is rejected, that is, $\mathrm{X}$ is the Granger cause of $\mathrm{Y}[6]$.

\section{DiscusSiOn OF EMPIRICAL RESEARCH RESUlTS}

Through analysis, the Granger causality test results are as follows.

According to the Table I, the relationship between the level of construction industry cluster and the diffusion of technological innovation is Grainger bidirectional causality in the 2 lag period. In addition, when lagging behind 1, 2, or 3 periods, the location entropy of Beijing construction industry is the Granger cause of labor productivity, which shows that the improvement of the degree of industrial clusters in the construction industry will promote the diffusion of technological innovation at some level.

According to the Table II, there is no Granger bidirectional causality between the labor productivity and the location entropy of the construction industry in Anhui Province when lagging behind 1, 2 or 3 periods. However, the location entropy of construction industry is the Granger cause of labor productivity when lagging behind 2 or 3 periods, which shows that the level of construction industry cluster in Anhui can promote the diffusion of technological innovation in construction industry to a certain extent.

TABLE I. RESULTS OF GRAINGER CAUSALITY TEST IN BEIJING

\begin{tabular}{|l|l|l|l|}
\hline \multicolumn{1}{|c|}{ Lag Period } & \multicolumn{1}{|c|}{ Null Hypothesis } & \multicolumn{1}{c|}{ F-statistics } & \multicolumn{1}{c|}{ P value } \\
\hline \multirow{3}{*}{1} & Labor productivity is not the cause of location entropy in construction industry & 0.12546 & 0.3317 \\
\cline { 2 - 5 } & Location entropy of construction industry is not the cause of labor productivity & 7.1704 & 0.0254 \\
\hline \multirow{2}{*}{2} & Labor productivity is not the cause of location entropy in construction industry & 0.45973 & 0.0465 \\
\cline { 2 - 5 } & Location entropy of construction industry is not the cause of labor productivity & 3.27862 & 0.0341 \\
\hline \multirow{2}{*}{3} & Labor productivity is not the cause of location entropy in construction industry & 0.66972 & 0.6010 \\
\cline { 2 - 5 } & Location entropy of construction industry is not the cause of labor productivity & 1.75104 & 0.0672 \\
\hline
\end{tabular}


TABLE II. RESULTS OF GRAINGER CAUSALITY TEST IN ANHUI

\begin{tabular}{|c|c|c|c|}
\hline Lag Period & Null Hypothesis & F-statistics & P value \\
\hline \multirow[t]{2}{*}{1} & Labor productivity is not the cause of location entropy in construction industry & 1.02310 & 0.3317 \\
\hline & Location entropy of construction industry is not the cause of labor productivity & 6.21345 & 0.0597 \\
\hline \multirow[t]{2}{*}{2} & Labor productivity is not the cause of location entropy in construction industry & 0.45973 & 0.6455 \\
\hline & Location entropy of construction industry is not the cause of labor productivity & 2.18206 & 0.0214 \\
\hline \multirow[t]{2}{*}{3} & Labor productivity is not the cause of location entropy in construction industry & 0.66972 & 0.0125 \\
\hline & Location entropy of construction industry is not the cause of labor productivity & 7.7149 & 0.0023 \\
\hline
\end{tabular}

TABLE III. RESULTS OF GRAINGER CAUSALITY TEST IN JIANGXI

\begin{tabular}{|l|l|l|l|}
\hline Lag Period & \multicolumn{1}{|c|}{ Null Hypothesis } & \multicolumn{1}{c|}{ F-statistics } & \multicolumn{1}{c|}{ P value } \\
\hline \multirow{3}{*}{1} & Labor productivity is not the cause of location entropy in construction industry & 1.02310 & 0.3317 \\
\cline { 2 - 5 } & Location entropy of construction industry is not the cause of labor productivity & 7.29371 & 0.0986 \\
\hline 2 & Labor productivity is not the cause of location entropy in construction industry & 0.45973 & 0.6455 \\
\cline { 2 - 5 } & Location entropy of construction industry is not the cause of labor productivity & 2.21976 & 0.0197 \\
\hline \multirow{3}{*}{3} & Labor productivity is not the cause of location entropy in construction industry & 0.66972 & 0.6010 \\
\cline { 2 - 5 } & Location entropy of construction industry is not the cause of labor productivity & 7.13101 & 0.0038 \\
\hline
\end{tabular}

According to the Table III, in lagging 1, 2 or 3 periods, Jiangxi labor productivity and construction industry location entropy does not constitute Granger two-way causal relationship. But the location entropy of construction industry is the Granger cause of labor productivity when lagging behind 2 or 3 periods, which indicates that the degree of construction industry cluster will promote the level of construction technology innovation diffusion to some degree.

\section{CONCLUSION}

To sum up, in Beijing, Anhui and Jiangxi, the construction industry cluster can promote the technological progress of the industry in the lag of 2 or 3 periods. And from the analysis results of Beijing, the diffusion of technological innovation can also promote the development of the construction industry cluster to a certain extent. Thus, it can be concluded that the construction industry clusters have a more obvious role in promoting the diffusion of technological innovation, and technology innovation diffusion has no significant impact on the industrial clusters in these areas.

Although the conclusion of this paper cannot be hold for all regions of China, we still hope that all local governments should be aware of the important role of industrial clusters in the diffusion of technological innovation. In one hand, the government-led construction industry cluster should be developed, that is, through the local government support and preferential policies, relying on the characteristics and foundation of the local construction industry, attract investment, attract the relevant enterprises into the construction industry cluster. At the same time, we should also pay attention to strengthen the close industrial relations among enterprises. If we cannot establish the corresponding division of labor and cooperation relationship, it is difficult to form the cluster effect if we only rely on the preferential policies of local government land and tax. In the other hand, market-oriented construction industry clusters should also be developed to create a good environment for technological innovation.

\section{REFERENCES}

[1] J.J. Fu, Y.F. Jiang, and J.S. Lei, Technological innovation, Beijing: Enterprise Management Press, 1992.

[2] W.X. Jin, Z. Hu, X.H. Lu, and D.Q. Yang, China's construction industry's new economic growth point and growth force, Beijing: China Construction Industry Press, 2008.

[3] A. Saxenian "Regional networks and the resurgence of Silicon Valley," California management review, vol. 33(1), pp. 89-112, 1990.

[4] F. Belussi and F.A. "A typology of networks: flexible and evolutionary firms," Research policy, vol. 27(4), pp. 415-428, 1998.

[5] Z.J. Sun and X.D. Ma, "Innovation, Technology Diffusion and Industrial Cluster Innovation and Development: A Model Proposal and Analysis," Guizhou Social Sciences, vol. 2012 (01), pp. 58-63.

[6] F.W. Sun, X.Cai, and M. Yu, "Granger causality test model analysis and application," Journal of Shenyang Architectural University (Natural Science Edition), vol. 2010 (02), pp. 405-408. 